УДК 581.192:634.738

\title{
СОДЕРЖАНИЕ МИКРОЭЛЕМЕНТОВ В ЯГОДАХ VACCINIUM VITIS-IDAEA В ЮЖНОМ ПРИБАЙКАЛЬЕ
}

\author{
(C) Л.В. Афанасьева \\ Институт общей и экспериментальной биологии СО РАН, ул. Сахьяновой, 6, \\ Улан-Удэ, 670047 (Россия), e-mail: afanl@mail.ru
}

\begin{abstract}
Изучены особенности накопления девяти микроэлементов (Mn, $\mathrm{Fe}, \mathrm{Zn}, \mathrm{Cu}, \mathrm{Co}, \mathrm{Cr}, \mathrm{Ni}, \mathrm{Pb}, \mathrm{Cd})$ в ягодах $V$. vitis$i d a e a$, произрастающей в разных типах леса на территории Южного Прибайкалья. Содержание микроэлементов определяли атомно-абсорбционным методом на спектрофотометре «AAnalyst 400 PerkinElmer». На основе средних концентраций составлен ряд накопления: $\mathrm{Mn}>\mathrm{Fe}>\mathrm{Zn}>\mathrm{Cu}>\mathrm{Cr}>\mathrm{Ni} \geq \mathrm{Pb}>\mathrm{Co} \geq \mathrm{Cd}$. Отмечено, что в большей степени условия произрастания влияют на содержание в ягодах $\mathrm{Mn}, \mathrm{Fe}, \mathrm{Cu}, \mathrm{Ni}, \mathrm{Cr}$. Выявлена корреляционная зависимость между содержанием кислоторастворимых форм $\mathrm{Fe}, \mathrm{Zn}, \mathrm{Cr}, \mathrm{Cd}$ в почве и в ягодах брусники $(r=0,53-0,78, p<0,05, n=15)$. На основе коэффициентов накопления выделены элементы сильного накопления растениями из почвы - $\mathrm{Mn}, \mathrm{Cu}, \mathrm{a}$ также элементы слабого накопления и среднего захвата - Fe, $\mathrm{Zn}, \mathrm{Cr}, \mathrm{Ni}, \mathrm{Pb}, \mathrm{Co}, \mathrm{Cd}$. Рассчитано, что 100 г сырых ягод V. vitisidaea могут обеспечить 50-160\% суточной потребности организма человека в $\mathrm{Mn}, \mathrm{Cr}$ и Сo.

Ключевые слова: Vaccinium vitis-idaea, ягоды, микроэлементы, Южное Прибайкалье.
\end{abstract}

Работа выполнена в рамках темы № VI.52.1.9. «Современное состояние разнообразия растительного покрова и его ресурсов в Байкальском регионе».

\section{Введение}

Ягоды брусники обыкновенной (Vaccinium vitis-idaea L. - сем. Vacciniaceae DC. Ex Perleb) широко используются в традиционной и народной медицине, фармакологии, пищевой и косметической промышленности. Благодаря наличию целого комплекса биологически активных веществ (органические кислоты, фенольные соединения, витамины, ферменты, полисахариды, дубильные вещества и др.) они обладают жаропонижающими, мочегонными, антибактериальными, тонизирующими, иммуномодулирующими свойствами [1].

В то же время известно, что фармакологическая активность лекарственных растений зависит не только от присутствующих в них биологически активных компонентов тех или иных типов, но обусловлена также способностью концентрировать отдельные биологически важные микроэлементы или их комплексы [2]. Микроэлементы выполняют функции активаторов биохимических процессов накопления, трансформации, переноса органических соединений в растениях. Поэтому наряду с изучением биохимического состава плодов важным представляется и исследование их элементного химического состава.

Несмотря на большое количество исследований, связанных с изучением химического состава ягод V. vitis-idaea [3], информации об уровне варьирования микроэлементов в зависимости от условий произрастания и локальных особенностей содержания в почве сравнительно мало [4-7]. Тогда как рассмотрение данного аспекта весьма актуально при решении вопросов о возможности использования плодов в качестве потенциальных источников биологически важных элементов для лечения и профилактики микроэлементозов. Многообразие условий произрастания может влиять на накопление микроэлементов в плодах и тем самым оказывать корригирующее действие на их питательную и витаминную ценность [2]. Кроме того, способность растительных организмов реагировать на колебания природных и антропогенных факторов увеличением вариабельности их химического состава рассматривается как одно из основных свойств растений, обеспечивающих их адаптацию к меняющимся условиям среды [8].

Афанасьева Лариса Владимировна - научный сотрудник лаборатории флористики и геоботаники, e-mail: afanl@mail.ru
Цель данной работы - изучить особенности накопления девяти микроэлементов ( $\mathrm{Mn}, \mathrm{Fe}, \mathrm{Zn}, \mathrm{Cu}$, $\mathrm{Co}, \mathrm{Cr}, \mathrm{Ni}, \mathrm{Pb}, \mathrm{Cd})$ в плодах V. vitis-idaea, произра- 
стающей в разных типах леса на территории Южного Прибайкалья, а также рассчитать количество микроэлементов, которое может поступить в организм человека с ягодами.

\section{Экспериментальная часть}

Исследования были выполнены на территории Южного Прибайкалья (северный макросклон хребта Хамар-Дабан), для которой характерны горный резко расчлененный рельеф, умеренно-континентальный влажный климат (годовое количество осадков - 900-1100 мм, средняя температура января $-16,5^{\circ} \mathrm{C}$, июля $12,1^{\circ} \mathrm{C}$ ) [9]. В почвенном покрове преобладают горно-таежные почвы: подбуры, подзолы и буроземы. В лесном поясе представлены кедрово-пихтовые, пихтовые, березовые, березово-сосновые леса зеленомошной, крупнотравной, папоротниковой и кустарничково-зеленомошной групп типов леса [10].

При изучении особенностей накопления химических элементов в ягодах $V$. vitis-idaea материал собирали в фазу полного их созревания в начале сентября в лесных сообществах, отличающихся условиями произрастания (табл. 1). Для каждого типа леса было заложено по три пробных площади, размером около 0,25 га. На пробных площадях методом квадрата отбирали пять точечных образцов, состоящих из 3-5 растений средневозрастного генеративного состояния. Одновременно отбирали почвенные образцы в перегнойно-аккумулятивном горизонте на глубину 0-20 см.

В лабораторных условиях проводили определение влажности плодов в 3-кратной повторности после их высушивания в сушильном шкафу до постоянной массы при температуре $105^{\circ} \mathrm{C}$. Основную часть растительных и почвенных образцов высушивали до воздушно-сухого состояния, после чего измельчали и просеивали. Перед выполнением аналитических работ в пробах определялась гигроскопическая влажность, для растений температура высушивания составляла $60^{\circ} \mathrm{C}$, для почв $-105^{\circ} \mathrm{C}$. Концентрации микроэлементов ( $\mathrm{Mn}, \mathrm{Fe}, \mathrm{Zn}, \mathrm{Cu}, \mathrm{Co}, \mathrm{Cr}, \mathrm{Ni}, \mathrm{Pb}, \mathrm{Cd}$ ) определяли атомно-абсорбционным методом на спектрофотометре «AAnalyst 400 PerkinElmer». В растительных образцах - после предварительного сухого озоления проб в муфельной печи при температуре $450{ }^{\circ} \mathrm{C}$ [11]. Из почвы извлекались потенциально подвижные (кислоторастворимые) формы металлов раствором $1 \mathrm{H}^{\mathrm{N} \mathrm{O}_{3}}$, при соотношении почвы к кислоте $1: 10$, время экстракции - 1 ч [12].

При оценке интенсивности накопления химических элементов ягодами из почвы были рассчитаны коэффициенты накопления $(K H)$ - отношение содержания элемента в плодах растений к содержанию его подвижных форм в почве. Для классификации элементов по этому коэффициенту были использованы выделенные А.И. Перельманом группы: 1) энергичного накопления (100>KH $\geq 10)$; 2) сильного накопления $(10>K H \geq 1) ; 3)$ слабого накопления и среднего захвата $(1>K H \geq 0,1) ; 4)$ слабого захвата $(0,1>K H \geq 0,01)$, 5) очень слабого захвата $0,01>K H \geq 0,001$ [13].

Статистическую обработку результатов проводили с использованием стандартных методов [14] и пакета программ Statistica 8.0. Для оценки достоверности различий средних значений исследуемых элементов использовали непараметрический критерий Краскела-Уоллиса.

Таблица 1. Краткая характеристика пробных площадей (ПП)

\begin{tabular}{|c|c|c|c|}
\hline $\begin{array}{c}\text { Номер } \\
\text { ПП }\end{array}$ & $\begin{array}{c}\text { Местоположение ключевого } \\
\text { участка }\end{array}$ & Тип леса & Краткая характеристика условий произрастания \\
\hline ПП-1 & $\begin{array}{c}\text { Иркутская обл., Слюдянский } \\
\text { р-н, окрестности с. Утулик }\end{array}$ & $\begin{array}{c}\text { Березняк } \\
\text { кустарничково- } \\
\text { зеленомошный }\end{array}$ & $\begin{array}{l}\mathrm{N}=51,52, \mathrm{E}=104,05, \mathrm{~h}=504 \text { м н.у.м. } \\
\text { Северный склон хребта Хамар-Дабан, } \\
\text { 6Б3С1Е, сомкнутость крон деревьев - 0,4-0,5, проек- } \\
\text { тивное покрытие брусники - 50-55\%, черники - 40- } \\
\text { 45\%. Почва подбур грубогумусированный }\end{array}$ \\
\hline ПП-2 & $\begin{array}{l}\text { Иркутская обл., Слюдянский } \\
\text { р-н, урочище Красный ручей }\end{array}$ & $\begin{array}{c}\text { Кедрово- } \\
\text { березовый травя- } \\
\text { но-сфагновый лес }\end{array}$ & $\begin{array}{l}\mathrm{N}=51,52, \mathrm{E}=104,11, \mathrm{~h}=482 \text { м н.у.м. } \\
0,5 \text { км от побережья оз. Байкал, северный склон хребта } \\
\text { Хамар-Дабан, 5К4Б1С, сомкнутость крон - 0,2, проек- } \\
\text { тивное покрытие брусники - 15-20\%, черника отдель- } \\
\text { ными кустами редко. Почва торфяная олиготрофная }\end{array}$ \\
\hline ПП-3 & $\begin{array}{c}\text { Республика Бурятия, Кабан- } \\
\text { ский р-н, окрестности } \\
\text { с. Клюевка }\end{array}$ & $\begin{array}{c}\text { Сосняк чернично- } \\
\text { зеленомошный }\end{array}$ & $\begin{array}{l}\mathrm{N}=51,67 \mathrm{E}=105,75, \mathrm{~h}=562 \text { м н.у.м. } \\
\text { Северный склон хребта Хамар-Дабан, 7С2Б1К, сомк- } \\
\text { нутость крон - 0,6-0,7, проективное покрытие черни- } \\
\text { ки - 60-65\%, брусники - 20-25\%. Почва дерново- } \\
\text { подзол. }\end{array}$ \\
\hline
\end{tabular}




\section{Результаты и их обсуждение}

Анализ полученных данных показал, что концентрации микроэлементов в ягодах $V$. vitis-idaea изменяются от 0,2 (Co, Cd) до 295 (Mn) мг/кг сухого вещества (табл. 2). При этом ряд накопления элементов, построенный на основе средних значений их концентрации, имеет следующий вид (в порядке убывания): $\mathrm{Mn}>\mathrm{Fe}>\mathrm{Zn}>\mathrm{Cu}>\mathrm{Cr}>\mathrm{Ni} \geq \mathrm{Pb}>\mathrm{Co} \geq \mathrm{Cd}$.

При оценке влияния условий произрастания на накопление микроэлементов в плодах $V$. vitis-idaea ориентировались на значения коэффициентов вариации $\left(C_{V}\right)$. Учитывая градации изменчивости для биологических объектов [14], можно сделать заключение о существенном влиянии абиотических факторов на накопление $\mathrm{Mn}, \mathrm{Fe}, \mathrm{Cu}, \mathrm{Ni}, \mathrm{Cr}$ в ягодах $V$. vitis-idaea.

Сравнительный анализ содержания микроэлементов в плодах $V$. vitis-idaea в разных типах леса выявил определенные различия в их концентрациях. Так, в березняке кустарничково-зеленомошном в плодах V. vitis-idaea содержится достоверно больше цинка, меди и хрома, в кедрово-березовом травяно-сфагновом лесу - железа, тогда как в сосняке чернично-зеленомошном ягоды отличаются более высокими концентрациями никеля, кобальта и кадмия, а содержание марганца, хрома в них, напротив, самое низкое.

Одной из причин различий концентрации микроэлементов в растениях может быть содержание их подвижных форм в почве. Анализ полученных данных показал, что торфяная почва характеризуется более низким содержанием марганца, цинка и кобальта, подбур - железа, тогда как концентрация марганца, цинка и хрома в нем самая высокая (табл. 2). При проведении корреляционного анализа отмечено, что между содержанием подвижных форм железа, цинка, хрома, кадмия в почве и их концентрацией в плодах V. vitisidaea обнаруживаются положительные связи среднего и высокого уровня значимости $(\mathrm{r}=0,53-0,78$, при $p<0,05)$, тогда как для свинца это связь была отрицательной $(\mathrm{r}=-0,58$, при $p<0,05)$.

Количественной мерой интенсивности накопления химических элементов растениями является коэффициент накопления (Кн), отражающий степень биофильности элементов, а также интенсивность их вовлечения в биологический круговорот. На основании полученных данных были выявлены элементы сильного накопления - $\mathrm{Mn}, \mathrm{Cu}\left(K_{H}=1,3-3,5\right)$, а также элементы слабого накопления и среднего захвата Fе, $\mathrm{Zn}, \mathrm{Cr}, \mathrm{Ni}, \mathrm{Pb}, \mathrm{Co}, \mathrm{Cd}\left(K_{H}=0,1-0,9\right)$ (табл. 3). При этом отмечено, что в кедрово-березовом травяносфагновом лесу интенсивность накопления $\mathrm{Mn}$ и $\mathrm{Zn}$ ягодами $V$. vitis-idaea была выше, чем в остальных типах леса, тогда как $\mathrm{Cu}$ интенсивнее накапливалась в ягодах растений березняка кустарничковозеленомошного.

Таким образом, полученные нами данные свидетельствуют о том, что химический состав ягод V. vitis-idaea подвержен существенной изменчивости, причем такие микроэлементы, как $\mathrm{Mn}, \mathrm{Cu}$ могут поступать в них безбарьерно, что, возможно, связано с их важной ролью в биохимических процессах. Исследованиями ряда авторов также показана способность некоторых металлов к перемещению в генеративные органы и семена [15-17], тогда как ранее считалось, что химические элементы накапливаются в репродуктивных органах по барьерному типу, так как строго генетически контролируются [18].

С точки зрения практического использования особого внимания заслуживает оценка качества плодов $V$. vitis-idaea, а также возможности их использования для лечения и профилактики микроэлементозов.

Таблица 2. Содержание микроэлементов ( $M \pm m$, мг/кг сухого вещества, $\mathrm{n}=15$, для каждой ПП) в ягодах $V$. vitis-idaea и в почвах (кислоторастворимые формы) на территории Южного Прибайкалья

\begin{tabular}{|c|c|c|c|c|c|c|c|c|c|}
\hline $\begin{array}{c}\text { Пробная } \\
\text { площадь (ПП) }\end{array}$ & $\mathrm{Mn}$ & $\mathrm{Fe}$ & $\mathrm{Zn}$ & $\mathrm{Cu}$ & $\mathrm{Ni}$ & $\mathrm{Cr}$ & $\mathrm{Pb}$ & Co & $\mathrm{Cd}$ \\
\hline \multirow[b]{2}{*}{ ПП-1 } & $295^{\mathrm{a}} *$ & $28,3^{c}$ & $10,2^{\mathrm{a}}$ & $6,2^{\mathrm{a}}$ & $\underline{1,3}^{\mathrm{b}}$ & $\underline{4,0^{\mathrm{a}}}$ & $\underline{0,7}$ & ${\underline{0,2^{b}}}^{\mathrm{b}}$ & ${\underline{0,2^{b}}}^{\mathrm{b}}$ \\
\hline & $158^{\mathrm{a}}$ & $\overline{142^{\mathrm{b}}}$ & $\overline{22,5^{\mathrm{a}}}$ & $\overline{3,3}$ & $\overline{3,9}$ & $\overline{8,1^{\mathrm{a}}}$ & $\overline{6,3}$ & $2,6^{\mathrm{a}}$ & 0,4 \\
\hline \multirow{2}{*}{ ПП-2 } & $\underline{287^{\mathrm{a}}}$ & $\underline{47,8^{\mathrm{a}}}$ & $\underline{8,7}^{\mathrm{b}}$ & $\underline{4,5}^{\mathrm{b}}$ & $\underline{1,5}^{\mathrm{b}}$ & $\underline{2,9}^{\mathrm{b}}$ & $\underline{0,6}$ & ${\underline{0,2^{b}}}^{\mathrm{b}}$ & ${\underline{0,2^{b}}}^{\mathrm{b}}$ \\
\hline & $83,1^{\mathrm{c}}$ & $237^{\mathrm{a}}$ & $9,2^{\mathrm{c}}$ & 3,6 & 4,1 & $\overline{6,1^{b}}$ & $\overline{7,3}$ & $1,8^{b}$ & $\overline{0,5}$ \\
\hline \multirow{2}{*}{ ПП-3 } & ${\underline{187^{\mathrm{b}}}}^{\mathrm{b}}$ & ${\underline{38,2^{b}}}^{\mathrm{b}}$ & $7,6^{\mathrm{b}}$ & $\underline{4,1}^{\mathrm{b}}$ & $\underline{1,9^{\mathrm{a}}}$ & $\underline{2,2^{\mathrm{c}}}$ & $\underline{0,6}$ & $\underline{0,3^{\mathrm{a}}}$ & $\underline{0,3^{\mathrm{a}}}$ \\
\hline & $114^{\mathrm{b}}$ & $254^{\mathrm{a}}$ & $12,3^{b}$ & 2,9 & 4,0 & $6,5^{b}$ & 6,4 & $2,5^{\mathrm{a}}$ & 0,5 \\
\hline$C V, \% *$ & 23 & 26 & 15 & 23 & 21 & 30 & 9 & 15 & 15 \\
\hline
\end{tabular}

Примечание: в числителе - концентрация элемента в ягодах, в знаменателе - концентрация элемента в почве. Буквами отмечены статистически значимые различия при $\mathrm{p}<0,05$, где $\mathrm{a}>\mathrm{b}>\mathrm{c}$. ${ }^{*} C V$ - коэффициент вариации. 
Таблица 3. Коэффициенты накопления (Кн) микроэлементов в ягодах V. vitis-idaea

\begin{tabular}{l|c|c|c}
\hline \multicolumn{1}{c|}{ Элемент } & $\Pi \Pi-1$ & $\Pi \Pi-2$ & $\Pi \Pi-3$ \\
\hline $\mathrm{Mn}$ & $\mathbf{1 , 9}$ & $\mathbf{3 , 5}$ & $\mathbf{1 , 6}$ \\
$\mathrm{Fe}$ & 0,2 & 0,2 & 0,2 \\
$\mathrm{Zn}$ & 0,5 & 0,9 & 0,6 \\
$\mathrm{Cu}$ & $\mathbf{1 , 9}$ & $\mathbf{1 , 3}$ & 0,4 \\
$\mathrm{Cr}$ & 0,5 & 0,5 & 0,1 \\
$\mathrm{~Pb}$ & 0,1 & 0,1 & 0,5 \\
$\mathrm{Ni}$ & 0,3 & 0,4 & 0,2 \\
$\mathrm{Co}$ & 0,1 & 0,1 & 0,6 \\
$\mathrm{Cd}$ & 0,5 & 0,4 & \\
\hline
\end{tabular}

Примечание: жирным шрифтом выделены элементы сильного накопления $(\kappa н>1)$.

Для оценки экологический безопасности ягод в настоящее время используют разработанные для свежих овощей, фруктов и ягод нормы предельно допустимых концентраций токсичных элементов $-\mathrm{Pb}$ (0,4 мг/кг сырой массы) и $\mathrm{Cd}(0,03$ мг/кг сырой массы) [19]. Установлено, что содержание этих элементов в ягодах, собранных на обследованной территории, ПДК не превышало и они могут быть использованы в пищевых и лекарственных целях.

При расчете содержания микроэлементов в 100 г свежих плодов V. vitis-idaea обнаружено, что при суточной потребности организма взрослого человека в жизненно необходимых микроэлементах [20] они могут обеспечить ее от $1,2 \%$ цинком до $160 \%$ марганцем (табл. 4).

Особый интерес представляет значительное удовлетворение потребности организма в марганце $(160 \%)$, хроме (100\%) и кобальте (50\%), с дисбалансом которых связано большое число заболеваний микроэлементозной этиологии [2]. Известно, что дефицит марганца приводит к хрупкости костей, нарушению образования хрящей, дерматитам, хрома - к развитию сахарного диабета II типа и сердечно-сосудистых заболеваний, кобальта - к нарушениям в функционировании нервной системы, анемии [21]. Учитывая полученные данные, ягоды V. vitis-idaea могут быть рекомендованы для коррекции и профилактики дефицита этих микроэлементов.

Таблица 4. Возможность использования ягод $V$. vitis-idaea в качестве источников микроэлементов для удовлетворения потребности взрослого человека

\begin{tabular}{c|c|c|c|c}
\hline Элемент & $\begin{array}{c}\text { Суточная потреб- } \\
\text { ность, мг/суг [20] }\end{array}$ & $\begin{array}{c}\text { Концентрация элемента, } \\
\text { мг/100 г сырого вещества }\end{array}$ & $\begin{array}{c}\text { \% от суточной по- } \\
\text { требности }\end{array}$ & $\begin{array}{c}\text { Верхний допустимый уро- } \\
\text { вень мг/сут }\end{array}$ \\
\hline $\mathrm{Mn}$ & 2,5 & 4,1 & $\mathbf{1 6 0}$ & 11 \\
$\mathrm{Fe}$ & 10 & 0,64 & 6,4 & 45 \\
$\mathrm{Zn}$ & 12 & 0,14 & 1,2 & 5 \\
$\mathrm{Cu}$ & 1,5 & 0,08 & 5,3 & 0,03 \\
$\mathrm{Co}$ & 0,01 & 0,005 & $\mathbf{5 0}$ & 0,25 \\
$\mathrm{Cr}$ & 0,05 & 0,05 & $\mathbf{1 0 0}$ & $\ldots$ \\
$\mathrm{Ni}$ & $0,2 *$ & 0,03 & 15 & $\ldots$ \\
\hline
\end{tabular}

Примечание: * данные для никеля приведены по [21].

\section{Bblвodbl}

В ходе проведенных исследований были определены средние концентрации девяти микроэлементов $(\mathrm{Mn}, \mathrm{Fe}, \mathrm{Zn}, \mathrm{Cu}, \mathrm{Cr}, \mathrm{Ni}, \mathrm{Pb}, \mathrm{Co}, \mathrm{Cd})$ в ягодах Vaccinium vitis-idaea $\mathrm{L}$., произрастающей в разных типах леса на территории Южного Прибайкалья. Отмечено, что в большей степени условия произрастания влияют на накопление в ягодах $\mathrm{Mn}, \mathrm{Fe}, \mathrm{Cu}, \mathrm{Ni}, \mathrm{Cr}$.

Выявлена корреляционная связь между содержанием кислоторастворимых форм $\mathrm{Fe}, \mathrm{Zn}, \mathrm{Cr}, \mathrm{Cd}$ в почве и в ягодах брусники $(r=0,53-0,78, p<0,05, n=15)$. На основе коэффициентов накопления выделены элементы сильного накопления растениями из почвы - $\mathrm{Mn}, \mathrm{Cu}$, а также элементы слабого накопления и среднего захвата $-\mathrm{Fe}, \mathrm{Zn}, \mathrm{Cr}, \mathrm{Ni}, \mathrm{Pb}, \mathrm{Co}, \mathrm{Cd}$.

Показано, что ягоды $V$. vitis-idaea могут быть использованы в качестве потенциального источника биологически важных микроэлементов $\mathrm{Mn}, \mathrm{Cr}$ и Сo. 


\section{Список литературы}

1. Рупасова Ж.А., Игнатенко В.А., Рудаковская Р.Н., Сидорович Е.А. Формирование биохимического состава брусники обыкновенной в Беларуси. Минск, 1998. 303 с.

2. Ловкова М.Я., Бузук Г.Н., Соколова С.М., Деревяго Л.Н. О возможности использования лекарственных растений для лечения и профилактики микроэлементозов и патологических состояний // Микроэлементы в медицине. 2005. Т. 6, №4. С. 3-10.

3. Лютикова М.Н., Ботиров Э.Х. Химический состав и практическое применение ягод брусники и клюквы // Химия растительного сырья. 2015. №2. С. 5-27.

4. Shaw G. Concentration of twenty-eight elements in fruting shrubs downwind of the smelter at Fin Flon, Manitova // Environmental Pollution. 1981. N25. Pp. 197-209.

5. Юдина В.Ф. и др. Брусника. М., 1986. 80 с.

6. Терентьева В.М. О минеральном составе ягод брусники // Наука и техника в Якутии. 2009. Т. 2, №17. С. $98-99$.

7. Бражная И.Э., Быкова А.Е., Судак С.Н., Семенов Б.Н. Исследование безопасности и минерального состава дикорастущего сырья Кольского полуострова // Вестник МГТУ. 2012. Т. 15. №1. С. 11-14.

8. Второва В.Н., Холопова Л.Б. Содержание микроэлементов в хвое ели обыкновенной в Подмосковье // Лесоведение. 2013. №2. С. 71-77.

9. Байкал : атлас / ред. Г.И. Галазий. М., 1993. 160 с.

10. Типы лесов гор Южной Сибири / под ред. В.Н. Смагина. Новосибирск, 1980. 334 с.

11. Методы биохимического исследования растений. Л., 1987. 430 с.

12. Теория и практика химического анализа почв / под ред. Л.А. Воробьевой. М., 2006. 400 с.

13. Перельман А.И. Геохимия. М., 1989. 528 с.

14. Зайцев Г.Н. Математика в экспериментальной ботанике. М., 1990. 296 с.

15. Hart J.J., Welch R.M., Norvell W.A., Sullivan L.A., Kochian L.V. Characterization of cadmium binding, uptake and translocation in intact seedlings of bread and durum wheat cultivars // Plant Physiol. 1998. Vol. 116. Pp. 1413-1420.

16. Arao T., Ae N., Sugiyama M., Takahashi M. Genotypic differences in cadmium uptake and distribution in soybeans // Plant Soil. 2003. Vol. 251. Pp. 247-253.

17. Кашин В.К., Убугунов Л.Л. О барьерности накопления микроэлементов в зерне злаковых культур // Доклады РАН. 2009. Т. 425, №3. С. 419-421.

18. Ильин В.Б. Элементный химический состав растений. Новосибирск, 1985. 129 с.

19. СанПиН 2.3.2.1078-01. Гигиенические требования безопасности и пищевой ценности пищевых продуктов. М., 2001. $180 \mathrm{c}$.

20. Методические рекомендации № 2.3.1. 1915-04. Рекомендуемые уровни потребления пищевых и биологически активных веществ. М., 2004. 34 с.

21. Диетология. 4-е изд. / под ред. А.Ю. Барановского. СПб., 2012. 1024 с.

22. Здоровье России : атлас / под ред. Л.А. Бокерия. М., 2007. 254 с.

Поступило в редакиию 15 марта 2016 г.

После переработки 4 апреля 2016 г. 
Afanasyeva L.V. CONTENT OF TRACE ELEMENTS IN VACCINIUM VITIS-IDAEA BERRIES IN SOUTHERN BAIKAL AREA

Institute of General and Experimental Biology SB RAS, ul. Sakhyanovoy, 6, Ulan-Ude, 670047 (Russia), e-mail: afanl@mail.ru

The aim of our study was to determine the trace element content (Mn, $\mathrm{Fe}, \mathrm{Zn}, \mathrm{Cu}, \mathrm{Co}, \mathrm{Cr}, \mathrm{Ni}, \mathrm{Pb}$ and $\mathrm{Cd}$ ) in Vaccinium vitis-idaea berries grown in the forest of Southern Baikal region. Element content was measured by atomic absorption spectrometry (AAS, AAnalyst 400 PerkinElmer). Results obtained indicated that the metals concentrations in the berries ranged from 0,2 (Co, Cd) to $295(\mathrm{Mn}) \mathrm{ppm}$. The row of the elements accumulation in the berries is: $\mathrm{Mn}>\mathrm{Fe}>\mathrm{Zn}>\mathrm{Cu}>\mathrm{Cr}>\mathrm{Ni} \geq \mathrm{Pb}$ $>\mathrm{Co} \geq \mathrm{Cd}$. According to the coefficients of accumulation the $V$. vitis-idaea berries acted as accumulators of $\mathrm{Mn}, \mathrm{Cu}(\mathrm{CA}>1)$ and excluders of $\mathrm{Fe}, \mathrm{Zn}, \mathrm{Cr}, \mathrm{Ni}, \mathrm{Pb}, \mathrm{Cd}, \mathrm{Co}(\mathrm{CA}<1)$. Significant correlations were found between content acid-soluble forms $\mathrm{Fe}, \mathrm{Zn}, \mathrm{Cr}, \mathrm{Cd}$ in the soil and berries $(\mathrm{r}=0,53-0,78, \mathrm{p}<0,05, \mathrm{n}=15)$. The toxic trace element analysis demonstrated that their content was safe for human consumption. We have concluded that $100 \mathrm{~g} \mathrm{~V}$. vitis-idaea berries can provide up to $50-160 \%$ of daily human nutrient requirement of $\mathrm{Mn}, \mathrm{Cr}$ and $\mathrm{Co}$.

Keywords: Vaccinium vitis-idaea, berries, trace elements, Southern Baikal region.

\section{References}

1. Rupasova Zh.A., Ignatenko V.A., Rudakovskaia R.N., Sidorovich E.A. Formirovanie biokhimicheskogo sostava brusniki obyknovennoi v Belarusi. [Formation of chemical composition cranberries ordinary in Belarus]. Minsk, 1998, 303 p. (in Russ.).

2. Lovkova M.Ia., Buzuk G.N., Sokolova S.M., Dereviago L.N. Mikroelementy v meditsine, 2005, vol. 6, no. 4, pp. 310. (in Russ.).

3. Liutikova M.N., Botirov E.Kh. Khimiia rastitel'nogo syr'ia, 2015, no. 2, pp. 5-27. (in Russ.).

4. Shaw G. Environmental Pollution, 1981, no. 25, pp. 197-209.

5. Iudina V.F. i dr. Brusnika. [Cowberry]. Moscow, 1986, 80 p. (in Russ.).

6. Terent'eva V.M. Nauka i tekhnika v Iakutii, 2009, vol. 2, no. 17, pp. 98-99. (in Russ.).

7. Brazhnaia I.E., Bykova A.E., Sudak S.N., Semenov B.N. Vestnik MGTU, 2012, vol. 15, no. 1, pp. 11-14. (in Russ.).

8. Vtorova V.N., Kholopova L.B. Lesovedenie, 2013, no. 2, pp. 71-77. (in Russ.).

9. Baikal. Atlas, ed. G.I. Galazii, Moscow, 1993, 160 p. (in Russ.).

10. Tipy lesov gor Iuzhnoi Sibiri. [Types of forest mountains of Southern Siberia]. ed. V.N. Smagin, Novosibirsk, 1980, 334 p. (in Russ.).

11. Metody biokhimicheskogo issledovaniia rastenii. [Methods of Biochemical Plant Research]. Leningrad, 1987,430 p. (in Russ.).

12. Teoriia $i$ praktika khimicheskogo analiza pochv. [Theory and practice of chemical analysis of soils]. ed. L.A. Vorob'eva. Moscow, 2006, 400 p. (in Russ.).

13. Perel'man A.I. Geokhimiia. [Geochemistry]. Moscow, 1989, 528 p. (in Russ.).

14. Zaitsev G.N. Matematika v eksperimental'noi botanike. [Mathematics in Experimental Botany]. Moscow, 1990, 296 p. (in Russ.).

15. Hart J.J., Welch R.M., Norvell W.A., Sullivan L.A., Kochian L.V. Plant Physiol, 1998, vol. 116, pp. $1413-1420$.

16. Arao T., Ae N., Sugiyama M., Takahashi M. Plant Soil. 2003, vol. 251, pp. 247-253.

17. Kashin V.K., Ubugunov L.L. Doklady RAN, 2009, vol. 425, no. 3, pp. 419-421. (in Russ.).

18. Il'in V.B. Elementnyi khimicheskii sostav rastenii. [Elemental chemical composition of plants]. Novosibirsk, 1985, 129 p. (in Russ.).

19. SanPiN 2.3.2.1078-01. Gigienicheskie trebovaniia bezopasnosti i pishchevoi tsennosti pishchevykh produktov. [SanPiN 2.3.2.1078-01. Hygienic requirements for safety and nutritional value of food products]. Moscow, 2001, 180 p. (in Russ.).

20. Metodicheskie rekomendatsii № 2.3.1.1915-04. Rekomenduemye urovni potrebleniia pishchevykh i biologicheski aktivnykh veshchestv. [Guidelines 2.3.1.1915-04. Recommended levels of consumption of food and biologically active substances]. Moscow, 2004, 34 p. (in Russ.).

21. Dietologiia. [Dietetics]. ed. A.Iu. Baranovskogo. SPb., 2012, 1024 p. (in Russ.).

22. Zdorov'e Rossii: Atlas. [Russian Health: Atlas]. ed. L.A. Bokeriia. Moscow, 2007, 254 p. (in Russ.).

Received March 15, 2016

Revised April 4, 2016 